\title{
Evaluation of the Locking Compression Plates Stress-Strain Fields
}

\author{
Uroš TATIĆ, Katarina ČOLIĆ, Aleksandar SEDMAK, Žarko MIŠKOVIĆ, Ana PETROVIĆ
}

\begin{abstract}
Locking Compression Plates (LCP) have found application in the orthopaedic healing process in modern medicine. Their design is specifically modified depending on the bone and the loading the specific bone is subjected to. Dimensions of LCP, as well as mechanical characteristics, provide greater structural resistance than the bone itself; in practice, however, continuous application and cyclic loading can lead to fails and fractures. Defining of the testing approaches and procedures used for the evaluation of the stress and location of geometrical areas with potential risk of the stress concentration represent the aim of this investigation. Results obtained in this paper show that combined use of modern experimental methods (DIC) and numerical simulations on the modified and simplified LCP geometry, can be used to locate stress and strain fields, as well as areas with stress concentration that can result in the appearance of cracks during cyclic loading.
\end{abstract}

Keywords: biomaterial; digital image correlation; FEM; fracture; Locking-Compression-Plates; stress strain evaluation; structural integrity

\section{INTRODUCTION}

Bone fractures (lat. Fracture) represent mechanical injury, which consists of fractures of bone as well as damage of surrounding soft tissue. These injuries occur due to external forces and loads with intensities exceeding the level of elasticity of the bone itself, thus causing its damage. Depending on age and global physical condition of the person, fractures can globally be divided into those

- occurring as a result of injury (excessive load),

- caused by degradation of the bone structure and tissue.

In present day's medicine, biomedical implants and orthopedic elements have found use in treating injuries and broken bones (joints, spine, etc.) as a substitute or additional support for bones and bone joints, either during the healing process or permanently. Metal alloys have found a wide application, due to mechanical properties.

The locking compression plate (LCP) represents effective bridging device used for treating fractures of the long bones by providing additional structural support during the healing process. It is positioned directly above fracture and connected to bone segments via bolts (Fig. 1).

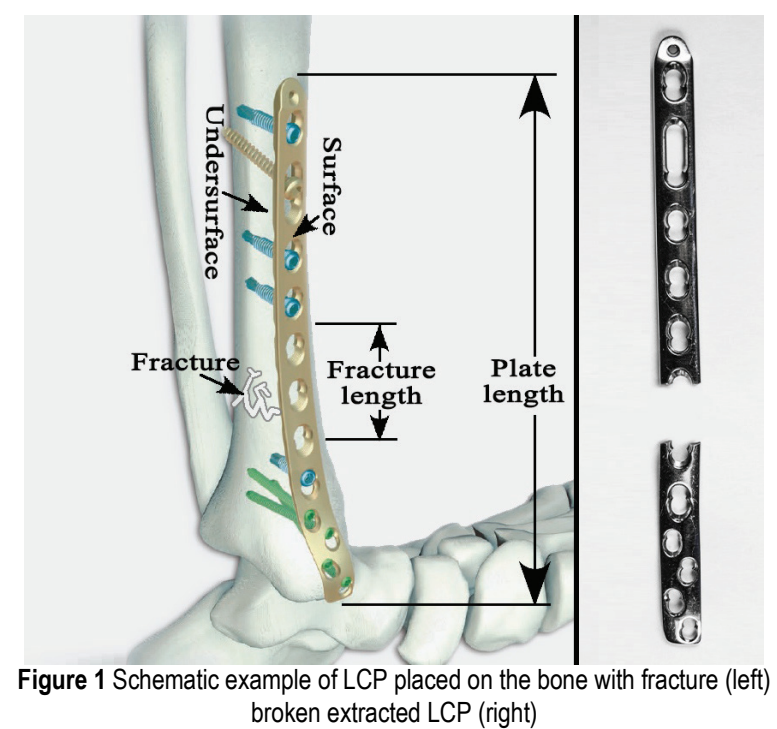

Figure 1 Schematic example of LCP placed on the bone with fracture (left) broken extracted LCP (right)

\subsection{Case Study - Orthopaedic Fixation Implants Fracture}

Experience from modern medical practice has shown that LCP can be used with high reliability and success rate. However, in certain cases, failure occurs in form of plate fracture, bending or loosening of screws and breaking of the rigid contact between plate undersurface and bone [1-5]. Here we present failure of LCP Stainless steel Metaphyseal Plate for left distal medial tibia, Fig. 1.

The purpose of the plate was to fixate the tibia during the bone healing period, and as such it was subjected to cyclic loads during normal exploitation, i.e. the patient's walking. Schematic example of plate positioning, as well as the view of a broken plate extracted from the patients are shown in Fig. 1.

\section{MATERIAL AND METHODS}

Biomaterials are used for production of medical equipment designed to be implanted into the human body, to replace damaged or diseased body parts. A biomaterial must be negative for carcinogenicity tests, cytotoxicity, must possess good chemical stability, i.e. corrosion resistance, and adequate mechanical properties, primarily dynamic strength. Orthopaedic biomaterials are above all limited to those materials that are used to produce parts with cyclic loading. Ideal metallic biomaterials should have: resistance to fatigue, high levels of yield strength, high levels of tensile strength and Corrosion resistance.

These characteristics are of significant importance in the development of fixating implants which are most often subjected to cyclic loading [6-8]. As the main function of bones in extremities is to carry the load, the task of orthopaedic plates is to provide support to bones with reduced integrity, and so the materials of choice for initial development of plates were metals. Biomaterial strength and stiffness significantly exceed those of the bone to which it is connected, and to which it provides additional support. Most commonly used metallic biomaterials $[9,10]$ for implants include: stainless steels, Co-Cr alloys and Titanium alloys.

Stainless steel alloys have been improved and nowadays, orthopaedic plates made of stainless steels with enhanced mechanical properties can be seen in practical application. Stainless steel 316L was developed during 
$1950 \mathrm{~s}$, wherein the carbon percentage was reduced from $0.08 \%$ in the case of previously used 316 steel to $0.03 \%$. Reduction of carbon percentage significantly improved corrosion resistance. In addition to carbon, steels 316 and $316 \mathrm{~L}$ were made with $18 \%$ chrome and $8 \%$ nickel. Advantages of stainless steels are primarily reflected in low percentage of impurities, which makes them ideal for use in vivo conditions. Their significant disadvantage compared to other superalloys is reflected in lower dynamic strength and vulnerability to erosion of the material itself, which, in case of developing of orthopaedic plates may have significant influence to their integrity and life.

Titanium alloys, Ti-6Al-4V and Ti-6Al-7Nb in particular, represent materials with currently most suitable mechanical properties, and are registered in ASTM standard as biomaterials $[9,11,12]$. Ti-6Al-4V alloy is made of $90 \%$ titanium, $6 \%$ aluminium and $4 \%$ vanadium. Such chemical composition is characterized by an extremely high corrosion resistance, high durability, favourable ratio between strength and weight $\left(4.43 \mathrm{~g} / \mathrm{cm}^{3}\right.$ [1]). Titanium is very resistant to corrosion due to a solid oxide layer (the only stable product of the reaction) which is formed in vivo conditions.

The main disadvantage of titanium alloys as biomaterials is the fact that they have a very high friction coefficient, which can lead to particle separation due to wear in the case of orthopedic components meant for direct contact. Ti-6Al-7Nb is a titanium alloy with a changed chemical composition, containing $7 \%$ niobium instead of vanadium, which is why it has an increased corrosion resistance in comparison to Ti-6Al-4V.

The numerical simulation was performed using finite element method (FEM). FEM represents the discretization of a physical model, i.e. its division into a finite number of smaller elements with their own initial volume, boundary conditions defined as displacements and/or loads, with simpler geometry. Initial simulations of LCP during in-vivo exploitation were performed numerally in order to simulate different loading conditions that can affect lifespan of plate.

Additional test specimens with specific geometrical elements were subjected to loading conditions according to the one expected during healing process. For the purpose of determining displacement and strain fields of test specimens, GOM equipment (GOM, Braunschweig, Germany) for three-dimensional strain measuring, along with the ARAMIS system and FEM simulations performed in SIMULIA Abaqus CAE (Dassault Systems) were used. Strain field is determined based on the change in mutual distance between predefined pixels on the measured specimen surface. In order to achieve the best definition of separate pixels while recording, measuring surface should be prepared to have a high contrast: the surface is painted a bright white colour with a black dot pattern spread over it (Fig. 2, bottom). Depending on the size and density of the black pattern, different volumes can be measured with the use of GOM system. In order to obtain as much deformation as possible, the measuring volume of $20 \times 20 \times 10 \mathrm{~mm}$ was chosen. This volume allows measuring the area only between two adjacent bolts. Comparison between FEM and DIC test models in the form of deformation field on the surface was used to verify successes of both methods. Furthermore, numerical models were used to estimate stress field inside the area, which was unable to be measured during experimental testing.

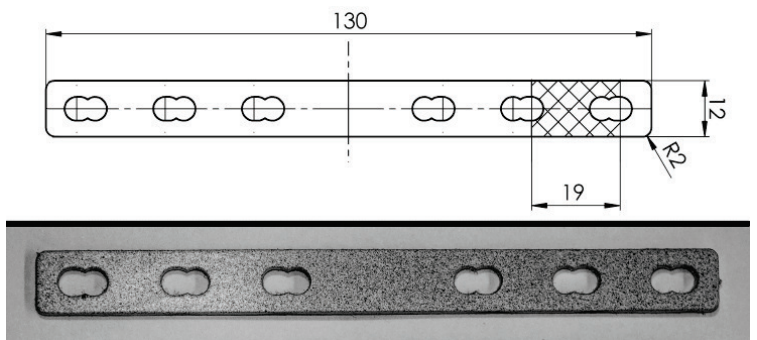

Figure 2 Schematic of the test plate with emphasized measuring area (top) Test plate prepared for measuring (bottom)

Table 1 Mechanical parameters of biomaterials and bones [6]

\begin{tabular}{|l|c|c|}
\hline \multicolumn{1}{|c|}{ Material } & $\begin{array}{c}\text { Elasticity } \\
\text { modulus } \\
E / \mathrm{GPa}\end{array}$ & $\begin{array}{c}\text { Tensile } \\
\text { strength } \\
\sigma_{\mathrm{t}} / \mathrm{MPa}\end{array}$ \\
\hline Bone Humid at lower load & 15.2 & 90 \\
\hline Bone Humid at higher load & 40.7 & - \\
\hline Stainless steel 316L & 193 & 540 \\
\hline Ti 0 \% porosity & 110 & 400 \\
\hline Ti-6Al-4V 0 \% porosity & 124 & 940 \\
\hline
\end{tabular}

\section{FEM SIMULATION OF IN-VIVO LOADINGS}

Numerical model of bone-plate assembly was created according to the geometry of the broken LCP and bone. Separate elements as bolts, plate and bone segments were created within Solidworks software (Dassault Systemes) and were exported to Abaqus where assembly was created. Each element was created as individual body. It is important to note that during the development of the bone segments gap of $1 \mathrm{~mm}$ was positioned between them.

Interaction between bolts and bone, as well as bolts and LCP was provided in a form of a tie constraint. Each contact was defined separately. Interaction between the LCP and bone was defined as surface to surface contact with tracking in the form of two configurations. Contact between separate parts of the bone was defined in the same way but with small sliding as well as adjustment in order to remove overclosure that could result as a consequence of deformation and lack of contact in the initial phase. Initial calculation step does not include contact between bone parts. Loading was applied in a form of axial force $(3000$ $\mathrm{N})$ corresponding to four times average human weights [6] while the articular surface on the tibia bone was restrained as encastre (Fig. 3).

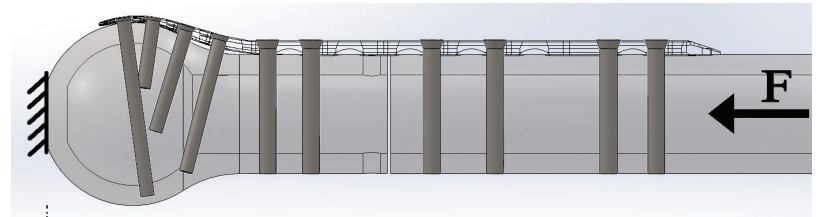

Figure 3 Schematic example of the LCP assembly, loading and boundary conditions

Due to a presence of a contact between bone segments (in the area away from LCP, Fig 4, bottom) during the later phases of loading, LCP was locally subjected to the tensile loading in the area directly above the fracture. Stress values can be seen in Fig. 4, top. Stress values at the undersurface of the LCP hole reached 
maximal values around $400 \mathrm{MPa}$, while the stress values at the bone segments contact reached only $90 \mathrm{MPa}$.

Observed results showed that LCP subjected to compression loading can have local tensile loadings which can result in stress values sufficient for growth of the crack and fracture of plate itself.
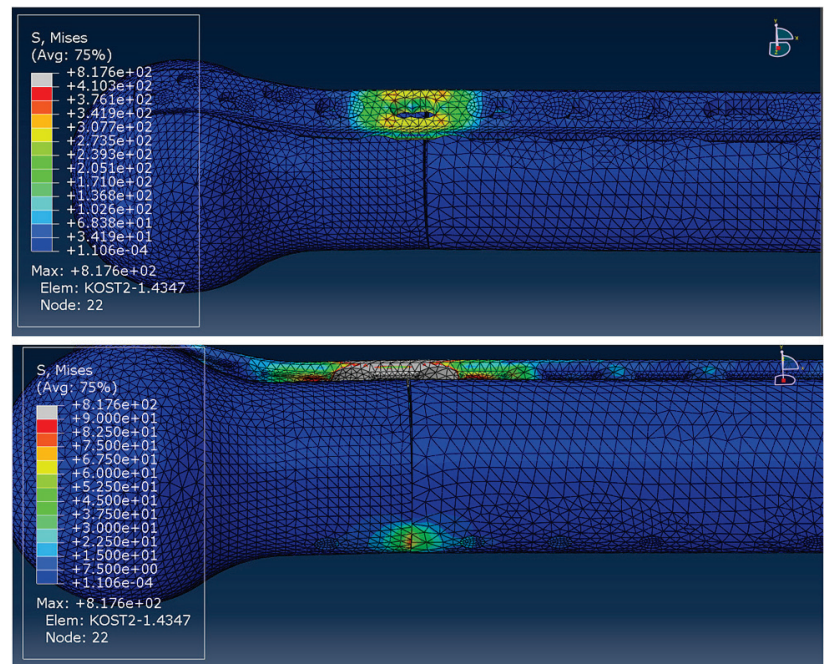

Figure 4 LCP stress values directly above the fracture (top), stress values at the contact area of the bone segments (bottom)

\section{EXPERIMENTAL SETUP}

Digital image correlation technique has found application in measuring of complex geometry as well as complex materials (bones, tissues, fibres) [13-18]. The experimental stage was designed to test the stress-strain distribution throughout the model in case of tensile loading (DIC). Finite element method is used to perform preclinical studies and testing as well as complex loading simulations present during a lifespan of implants [19-23]. In parallel to the experimental specimen, numerical models were created in order to compare gained deformation results on the measured surface (FEM) and provide better insight into stress field.

New plate with simulated combination hole (allows an internal fixation using standard screws, angle-stable locking head screws, or a combination of both, which takes into account the most diverse intraoperative requirements) geometry made out of a Ti-6Al-4V was created to eliminate any influence of the other geometrical properties in the design of the plate (Fig. 2). The plate was cut using the water jet technique to prevent development of potential micro cracks caused by the machining.

Testing was performed on both the pig bones and on the wood specimens in order to adjust equipment and to define measuring parameters. The aim of this approach was to verify that stress-strain field will have the same distribution on both materials in order to simplify further experiments.

The experimental setup can be seen in Fig. 5. The plate was positioned on two separate wood pipes/bones. Each was connected with three bolts to the LCP plate. Using this configuration, bone breakage was simulated in the middle section of the LCP. This setup was chosen to provide adequate and equal stress-strain field on both sides of the LCP.
Load from the wood pipes/bones was to the tensile machine via the metal plates positioned on the end of the pipes. During the initial testing phase it was determined that these plates should be positioned in the same plane as the LCP instead of the middle plane of the pipes/bones in order to prevent bending in the middle of the LCP (directly above the simulated brakeage).

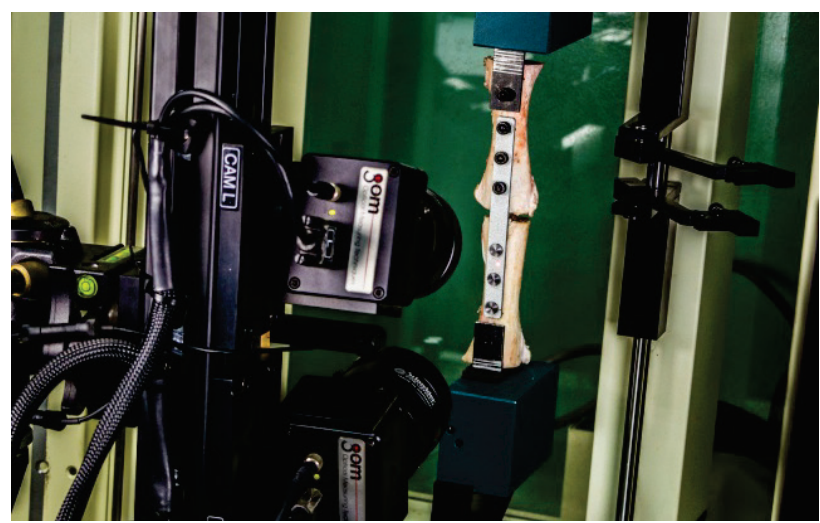

Figure 5 Experimental setup on the pig bone specimen

Although the bones were connected to the edge plate used for translating load with only one bolt, and to the LCP plate with three separate bolts, this had a local character on bone, which was not of significant importance for the experimental results. Results of this setup would have a larger stress concentration on the outer edge of the pipe/bone, but it would not have any influence on the mutual stress-strain influence of the LCP and pipe/bone due to the fact that an equal loading would be transmitted to the three bolts as the loading on the one top bolt. The load was gradually increased to maximum value of $1607 \mathrm{~N}$ for a wood specimen and $1621.5 \mathrm{~N}$ for a bone, while the speed of deformation was $2 \mathrm{~mm} / \mathrm{min}$. Loading was stopped before the failure of the pipes accrued.

\section{MEASURING PROCEDURES AND NUMERICAL EVALUATION}

Stress-strain field on the surface of the model was measured using digital image correlation-based GOM measuring system [24-26].

In order to increase the measuring field, reduce light reflections and provide more uniform light distribution throughout the measured area, two separate light sources were positioned on each side of the measured specimen, at the same height as cameras that were used. Furthermore, bolt heads were made with reduced thickness, mostly to reduce presence of the shadows and enlarge measuring area. Measuring of the stress-strain field was performed separately in the areas between the bolts one and two as well as bolts two and three. The size of the measuring area between bolts 2 and 3 can be observed as the crosshatched area in Fig. 2.

Due to geometrical conditions (double symmetry in geometry and loading conditions) FEM simulation of the test models was performed on the quarter of the real model. Models were created as two body models. One body represented bone as well as bolts (during the development of the mesh body was separated into 4 different areas, three bolts and bone, which were 
connected via Tie constraint connection due to different elements used) while the other one was made to replicate the LCP plate. Due to symmetry approximation, restrains were added on both planes of symmetry (longitudinal and lateral). Loading was positioned in a form of a concentrated force with magnitude of $375 \mathrm{~N}$. Compatibility of DIC and FEM models was determined by deformation comparison in the lateral direction between two opposite bolts.

\section{RESULTS AND DISCUSSION}

Results obtained with DIC, together with results of numerical models, can be seen in Figure 6 and 7. Initial expectation for LCP plate loading for distal medial tibia was compression due to position in the body as well as loading present within a bone during healing process. FEM simulation of in-vivo loading has shown that stress strain distribution can be affected with small imperfections during the surgical repositioning of bone segments and positioning of the plate. Small gap present between the bone segments before positioning of LCP can produce local tensile load present on the plate directly above the fracture during the highest values of loading. Asymmetric positioning of the plate (positioning of the plate on one side of the bone) produces initial bending during the first phase of the loading while the gap is present. After the contact between the bone segments has been established, length of the bone acts as a lever causing a plate to be locally subjected to tensile loading around the hole positioned above the fracture gap. Simulated loading conditions can produce cleaving of the crack present in the LCP area without bolts, which can potentially lead to a failure and breakage. Highest stress values for the LCP were located at the subsurface area of the hole, $410 \mathrm{MPa}$ at the exact failure location. Bone segments contact area had a stress value of only $90 \mathrm{MPa}$ due to increase of contact area with loading.

Metaphyseal LCP for distal medial tibia is produce both of stainless steel 316L and titanium alloy Ti-6Al-4V with identical geometry.

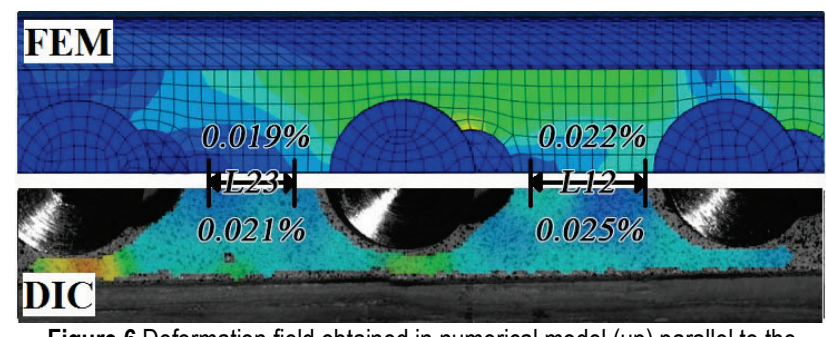

Figure 6 Deformation field obtained in numerical model (up) parallel to the results obtained with DIC (bottom) on a wood specimen

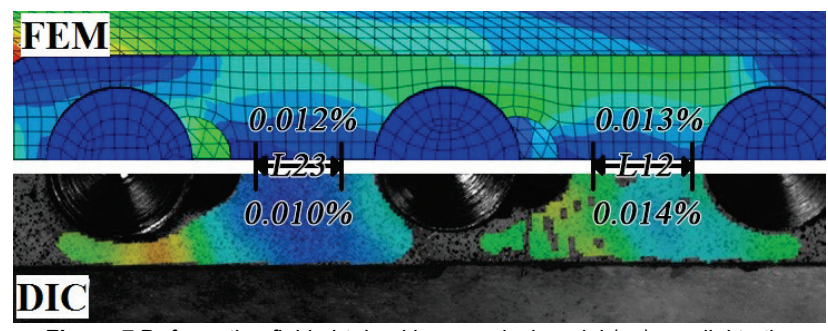

Figure 7 Deformation field obtained in numerical model (up) parallel to the results obtained with DIC (bottom) on a bone specimen
Experimental testing performed on the test models was created to determine stress concentration based on the geometrical design of the plate. Experiment was performed on the Ti-6Al-4V samples due to their mechanical properties and higher risk for brittle fracture. Setup is designed with focus on the mutual influence of the bone and LCP, stress transfer between them and measuring of the differences between separate areas of the LCP as well as the bolts. In case of wood model, deformation in the lateral direction between bolts 1 and 2 (L12) was measured to be $0.022 \%$ with a use of DIC measuring, while with a use of FEM deformation was calculated at $0.025 \%$, between bolts 2 and 3 (L23) it was $0.019 \%$ using DIC and 0.021 $\%$ with a use of FEM (Fig. 6). In case of bone model deformation in the lateral direction between bolts 1 and 2 (L12) was measured $0.013 \%$ with a use of DIC measuring, while with a use of FEM deformation was calculated at $0.014 \%$, between bolts 2 and 3 (L23) it was $0.012 \%$ using DIC and $0.010 \%$ with the use of FEM (Fig. 7).

Deformation fields for both specimens have a similar distribution, both in the real experiment and the numerical simulation. Maximal deformation values are located at the edge of the hole, at the exact position of the fracture of LCP.

After the comparison between FEM and DIC methodology results, on the top side of the plate, numerical models were used to determine Mises stress fields throughout a model due to restrictions of the DIC. Stress field for a wood model showed stress values of $150 \mathrm{MPa}$ at the edge of hole 2 at top side (LCP surface) while the maximum stress values of $270 \mathrm{MPa}$ at the bottom (LCP, subsurface) were located at the edge of hole 1 at the exact place of the fracture (Fig. 8, bottom). Stress concentration on both models as well as both methodologies has similar results. Deformation between bolts 1 and 2 has $2 \%$ to 5 $\%$ bigger values than deformation between bolts 2 and 3 . Stress field for a bone model showed concentration of 114 $\mathrm{MPa}$ on the edge of the hole 2 on the top side (LCP surface) while the maximum stress values of $221 \mathrm{MPa}$ on the bottom (LCP, subsurface) were located at edge of hole 1 (Fig. 9, bottom). Difference in the elasticity module for a wood and bone affected different maximal values due to complex behaviour of the assembly and different deformation field of the elements in contact. Procedure for the evaluation of the stress-strain field shown above represents collaboration of different engineering tools and techniques used to provide insight in the behaviour of the medical equipment during different stages of the loading in real life exploitation as well as testing conditions. Loading conditions used represent the worst case scenario to which one LCP plate can be subjected.

Preparation of the LCP specimen is made with the aim to reduce any additional influence of the geometry that can be present on the real life LCP. Preparation of the experiment can be performed with ease in cases of artificial bone replacement materials used (wood), while the measurements on the real bones can be performed afterwards with similar values. It should be noted that bone parameters can significantly vary, depending on the age, sex and physical condition of the patient. 


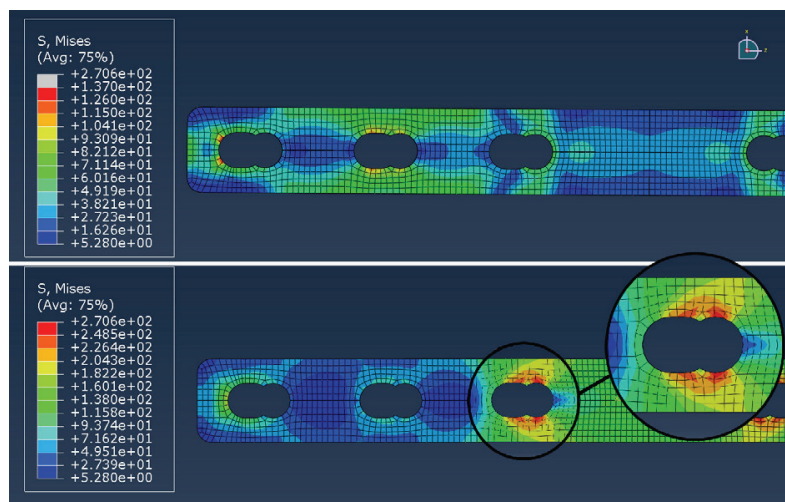

Figure 8 LCP surface stress field (top) LCP subsurface stress filed (bottom) on a wood specimen

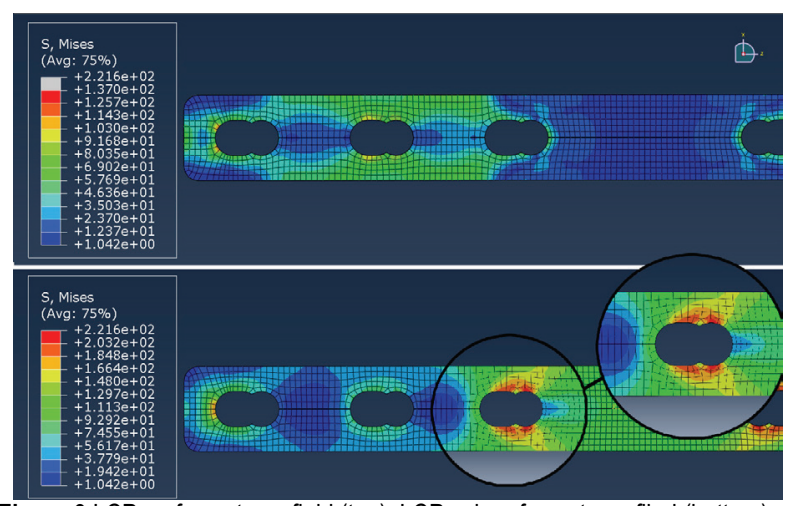

Figure 9 LCP surface stress field (top), LCP subsurface stress filed (bottom) on a bone specimen

Replacement of the bone with an artificial material, as it was a case of wood, can provide basic insight in the stress-strain behaviour, distribution and values. Module of elasticity for the oak wood used throughout testing phase was around $11 \mathrm{GPa}$. It must be noted that testing with any organic material requires additional testing and evaluation of a material duo to the non-homogeneity of the materials used.

During the testing phase it was noticed that due to relatively small area of the LCP observed in comparison to a whole specimen (LCP, simulated bones, connecting plates), local displacement would be much higher at the area of the LCP connected to the moving jaws of the tensile machine. In a case of DIC measuring, all specimens should be positioned in the way that the measured areas are as close as possible to the stationary jaws. Further away from the fixated end global displacement of the whole model becomes greater in comparison to local displacement of the LCP, which can result in relocation of the measured area away from the range of DIC volume.

Geometry of the holes as well as outer geometry can have a major role on stress concentration that can lead to appearance of fatigue cracks during the cyclic loading present in the healing process.

\section{CONCLUSION}

Numerical simulations have shown that depending on the position of fracture, fracture shape and adequate relocation of the bone segments during the surgery complex loadings can be present in the local areas of the LCP and bone. Maximal stress values have been located at the subsurface of the LCP in the area of the hole, fracture location of real LCP model.

With the use of the shown evaluation procedure and methodology a stress-strain field for a local area of LCP can be obtained. Adequate preparation of the specimen has a major role in later experiment. Calibration area of $20 \times 20$ $\times 10 \mathrm{~mm}$ provides best local results due to complex geometrical elements of LCP combination hole. Data obtained at the surface of specimen with DIC method showed the stress values during experiment were approximately two times smaller in the measured area than the numerically obtained on the subsurface side. Experimental setup can be used to replicate different geometries of the LCP as well as different bone material. Experimental results have shown that both wood and pig bone model can be used to replicate initial preclinical testing in the area of elastic deformation due to their similar material properties as well as heterogeneity.

Initial testing performed on wood has a major advantage in the further experimental process with real bones due to the fact that the specimen, as well as the experimental setup, can be prepared in advance, which allows for fast execution of the experiment. Data acquired through this experiment has shown maximal stress values located at the place of fracture of the clinically used LCP, subsurface area of LCP combined hole in a case of both models. Values on the top side are obtained both numerically and experimentally.

In order to obtain adequate results for the real behaviour of LCP, experiments should be performed with different LCP geometries as well as with a real bone in order to have a better insight into load distribution between bone and plate.

All testing results indicated stress concentration at the location of the "combine hole" due to a weakening of the cross section as well as change in the geometry. Numerical simulations as well as the experimental testing have proven that during the maximal loading stress values remain within the elastic deformation. Location of the stress concentration and fracture is directly in the proportion with a mutual position of the fracture and LCP.

In the case that bone segments are positioned with a small gap, presence of the cyclic loading can lead to a compression in the early stage before the contact of segments is achieved and to tensile loading when the contact is present in later stage. These types of loading represent ideal conditions for development of micro cracks.

Presence of local tensile loading on the hole directly above the bone fracture provides cleaving conditions for a crack growth, and development of brittle fracture.

\section{Acknowledgements}

The study was carried out within Project TR -35040 , financed by the Ministry of Education, Science and Technological Development, Republic of Serbia.

\section{REFERENCES}

[1] Guerra-Fuentes, L., Garcia-Sanchez, E., Juarez-Hernandez, A. \& Hernandez-Rodriguez, M. A. L. (2015). Failure analysis in $316 \mathrm{~L}$ stainless steel supracondylar blade plate. Engineering Failure Analysis, 57, 243-247. 
https://doi.org/10.1016/j.engfailanal.2015.07.033

[2] Fariba N., Hassan F., Maryam Zahiri, Azar \& Ali Ammari, Allahyari. (2007). Fractographic investigation of failures in 316L stainless steel orthopedic condylar blade plate. Prooceedings of $8^{\text {th }}$ International Fracture Conference, 585592.

[3] Ali, A., Ali, S., Salman, H. A., Farid, Z. \& Mateen, M. A. (2009). Broken Orthopaedic Implant: An Experience at PIMS. Ann. Pak. Inst. Med. Sci., 5(3), 136-140.

[4] Kanchanomai, C., Phiphobmongkol, V. \& Muanjan, P. (2008). Fatigue failure of an orthopedic implant - A locking compression plate. Engineering Failure Analysis, 15, 521530. https://doi.org/10.1016/j.engfailanal.2007.04.001

[5] Petković, D., Radenković, G. \& Mitković, M. (2012) Fractographic investigation of failure in stainless steel orthopedic plates. Mechanical Engineering, 10(1), 7-14

[6] Ratner, B. D., Hoffman, A. S., Schoen, F. J. et al. (1996). Biomaterials Science an Introduction to Materials in Medicine, San Diego: Academic Press.

[7] Milne, I., Ritchie, R. O. \& Karihaloo, B. (2003). Comprehensive Structural Integrity, Oxford: Elsevier Ltd.

[8] Park, J. B. \& Lakes, R. S. (1992). Biomaterials an Introduction, New York: Plenum Press. https://doi.org/10.1007/978-1-4757-2156-0_1

[9] ASTM F136-11 Standard Specification for Wrought Titanium 6Aluminum 4Vanadium ELI (Extra Low Interstitial) Alloy for Surgical Implant Applications, (UNS R56401).

[10] ASTM F139-08 Standard Specification for Wrought 18Chromium 14Nickel 2.5Molybdenum Stainless Steel Sheet and Strip for Surgical Implants, (UNS S31673).

[11] ASTM F1108-04(2009) Standard Specification for Titanium 6Aluminum 4Vanadium Alloy Castings for Surgical Implants (UNSR56406).

[12] ASTM F1295-11 Standard Specification for Wrought Titanium 6Aluminum 7Niobium Alloy for Surgical Implant Applications (UNSR56700).

[13] Xue, Y., Cheng, T., Xu, X., Gao, Z., Li, Q., Liu, X., Wang, X., Song, R., Ju, X. \& Zhang, Q. (2017). High-accuracy and real-time $3 \mathrm{D}$ positioning, tracking system for medical imaging applications based on 3D digital image correlation. Optics and Lasersin Engineering, 88, 82-90. https://doi.org/10.1016/j.optlaseng.2016.07.002

[14] Väänänen, S. P., Yavari, S. A., Weinan, H., Zadpoor, A. A., Jurvelin, J. S. \& Isaksson, H. (2013). Repeatability of digital image correlation for measurement of surface strains in composite long bones. Journal of Biomechanics, 46, 19281932. https://doi.org/10.1016/j.jbiomech.2013.05.021

[15] Luyckx, T., Verstraete, M., De Roo, K., De Waele, W., Bellemans, J. \& Victor , J. (2014). Digital image correlation as a tool for three-dimensional strain analysis in human tendon tissue. Luyckx et al. Journal of Experimental Orthopaedics. https://doi.org/10.1186/s40634-014-0007-8

[16] Omkar, S. N., Praveen G. B. \& Singh, A. (2013). Analysis of Wrist Extension Using 3D Digital Image Correlation. Biomedicine and Biotechnology, 1(1), 1-7.

[17] Sztefek, P., Vanleene, M., Olsson, R., Collinson, R., Pitsillides A. A. \& Shefelbine, S. (2009). Using digital image correlation to determine bone surface strains during loading and after adaptation of the mouse tibia. Journal of Biomechanics.

[18] Milosevic, M., Milosevic, N., Sedmak, S., Tatic, U., Mitrovic, N., Hloch, S. \& Jovicic, R. (2016). Digital image correlation in analysis of stiffness in local zones of welded joints. Technical gazette, 23(1), 19-24.

[19] Izham, R. M. A. R., Kadir, M. R. A., Rashid, A. H. A., Hossain, Md. G. \& Kamarul, T. (2012). Finite element analysis of Puddu and Tomofix plate fixation for open wedge high tibial osteotomy. Injury, Int. J. Care Injured, 43, 898902. https://doi.org/10.1016/j.injury.2011.12.006
[20] Salas, C., Mercer, D., DeCoster, T. A. \& Taha M. M. R. (2010). Experimental and Probabilistic Finite Element Analysis of Distal Femoral Fractures: A Comparison of locking plate versus intramedullary nail fixation. Proceedings of the ASME 2010 Summer Bioengineering Conference. https://doi.org/10.1115/SBC2010-19303

[21] Yang G., Partridge, K. A., Abdel-Mohti, A., McMullen, A. J. \& Shen, H. (2016). Finite Element Analysis of Osteotomy Treatment for Kienbock's Disease. Biomedical Science and Engineering. https://doi.org/10.4236/jbise.2016.910B021

[22] Nia, M.; Niuc, W.; Wai-Chi Wongd, D.; Zenge, W.; Meia, J.; Zhangd, M. (2016). Finite element analysis of locking plate and two types of intramedullary nails for treating mid-shaft clavicle fractures. Injury, Int. J. Care Injured, 47, 1618-1623. https://doi.org/10.1016/j.injury.2016.06.004

[23] Cai, X., Yu, Y., Liu, Z., Zhang, M., Huang, W. (2014). Three-dimensional finite element analysis of occipitocervical fixation using an anterior occiput-to-axis locking plate system: a pilot study. The Spine Journal, 14, 1399-1409. https://doi.org/10.1016/j.spinee.2013.08.025

[24] Peters, W. H. \& Ranson, W. F. (1982). Digital imaging techniques in experimental stress analysis. Optical Engineering, 21, 427-431. https://doi.org/10.1117/12.7972925

[25] Fard, M. Y., Liu, Y. T., Chattopadhyay, A. (2012). Characterization of Epoxy Resin Including Strain Rate Effects Using Digital Image Correlation System. $J$. Aerospace Eng., 2, 308-319. https://doi.org/10.1061/(ASCE)AS.1943-5525.0000127

[26] Sedmak, A.; Milosevic, M.; Mitrovic N., Petrovic A. \& Maneski, T. (2012). Digital image correlation in experimental mechanical analysis. Structural Integrity and Life, 1, 39-42.

\section{Contact information:}

Uroš TATIĆ, Corresponding author

Innovation Center of Faculty of Mechanical Engineering

Kraljice Marije 16, 11000 Belgrade, Serbia

taticuros@gmail.com

\section{Katarina ČoLIĆ}

Innovation Center of Faculty of Mechanical Engineering

Kraljice Marije 16, 11000 Belgrade, Serbia

kcolic@mas.bg.ac.rs

\section{Aleksandar SEDMAK}

Faculty of Mechanical Engineering

Kraljice Marije 16, 11000 Belgrade, Serbia

asedmak@mas.bg.ac.rs

\section{Žarko MıšKović}

Faculty of Mechanical Engineering

Kraljice Marije 16, 11000 Belgrade, Serbia

zmiskovic@mas.bg.ac.rs

\section{Ana PETROVIĆ}

Faculty of Mechanical Engineering

Kraljice Marije 16, 11000 Belgrade, Serbia

aspetrovic@mas.bg.ac.rs 